This is a self-archived - parallel published version of this article in the publication archive of the University of Vaasa. It might differ from the original.

\title{
Service Supply Chain Design by Using Agent-Based Simulation
}

Author(s): Helo, Petri; Rouzafzoon, Javad; Gunasekaran, Angappa

Title: $\quad$ Service Supply Chain Design by Using Agent-Based Simulation

Year: $\quad 2018$

Version: final draft (post print, aam)

Copyright (C) The Editor(s) (if applicable) and The Author(s), under exclusive license to Springer International Publishing AG, part of Springer Nature 2018

\section{Please cite the original version:}

Helo P., Rouzafzoon J., \& Gunasekaran A. (2018). Service Supply Chain Design by Using Agent-Based Simulation. In: Kohtamäki M., Baines T., Rabetino R., Bigdeli A. (eds) Practices and Tools for Servitization. Palgrave Macmillan, Cham. https://doi.org/10.1007/978-3-319-76517-4_21 


\title{
SERVICE SUPPLY CHAIN DESIGN BY USING AGENT BASED SIMULATION
}

\author{
Petri Helo, University of Vaasa, Networked Value Systems, Vaasa, Finland \\ Javad Rouzafzoon, University of Vaasa, Networked Value Systems, Vaasa, Finland \\ Angappa Gunasekaran, California State University Bakersfield, Bakersfield, USA
}

\begin{abstract}
Supply chain management is an important function in the service delivery. It comprises of physical materials and tools needed as well as intangible operational parts. The process of designing service supply chains is a task combining the aspects of customer-server interaction, resourcing and service delivery. Operational and structure related decisions are evaluated by using key performance indicators. Agent based modelling (ABM) offers a possibility to simulate the behaviour of such system. Customers and servers can be modelled as agents obeying rules and operating in a common world. Interactions and events may occur based on agent type, geographic location or past events. ABM approach can answer what-if questions or test the limit conditions of a designed delivery system.
\end{abstract}

Keywords: Service supply chain, agent based modelling, simulation.

\section{INTRODUCTION}

Supply chain management plays a significant role in industrial product-service-systems (PSS). Physical products are part of the entire delivery and intangible components of the delivery are becoming increasingly important, when companies are transforming to servitization. Operations, including tangible or intangible elements, are distributed in different locations and among different actors. Supply chain management encompasses activities aiming efficiently running, monitoring and improving the performance of a supply chain. The traditional supply chain is concerned to all activities associated with conversions and flow of goods and services including funds and data flows from material sources to final users. Service supply chain includes planning and controlling activities from support functions to end-users, and development and modelling methods designed for operations management can be utilized in service supply chains. Service supply chains have been studied in various industries to create frameworks and modelling system-wide effects such as demand pattern changes.

Responding instantly to the demand variability is the most significant challenge for service organizations. There are several differences between service and manufacturing supply chain, but the most significant one is that fulfilling demands variability by creating inventory is not possible, but other approaches such as queueing, generating backlog and creating reservation systems may take place in service organizations. Agent-based modelling presents an efficient approach for the assessment of management decision options. This approach allows the use of geographical information systems, i.e. maps, to provide the opportunity for analysing heterogeneity of spatial elements, which can be population densities, road networks and landscape features.

Industrial companies moving toward product-service-systems need to take account scenarios of delivery and plan how to maintain good asset utilisation at the same time. Smart connected installed base is offering a possibility to see actual operations as well as raw data for analysing service demand and delivery. It is getting more common to have industrial companies where the business model is based on subscriptions and delivered service transactions only instead of one-time delivery of goods. This chapter presents possibilities of using agent-based simulation in service supply chain design by providing an illustrative example of service simulation modelling. 


\section{THEORY}

\subsection{Service supply chain characteristics}

Traditional supply chains are managed by industrial companies by using material handling oriented tools such as Enterprise Resource Planning (ERP) or Advanced Scheduling and Planning (APS) systems. In the servitization context, new solutions are needed to consider the service delivery aspects. Service supply chains are defined as a network of service units that can fulfil one or more service tasks as required. Three major elements in service supply chain structure can be described as: (1) service providers who present standardized, single service-type of companies and utilize collaboration and cooperation; (2) service integrators who are the primary enterprises in service supply chains and with access to efficient data processing and robust service design capability, facilitate collaboration and integration of tailored services presented by service providers to users; and (3) customers who can be an individual or a firm and service supply chain performance requirements are defined based on customers' needs (Sakhuja, Jain, Kumar, \& Chandra, 2016).

Service supply chains have unique characteristics compared to supply chains focusing on material movements. In service supply chains, the service performance relies upon customers and subcontractor input into service production and delivery. These inputs can be managed or specified by contracting and inducement systems. Contracting can be considered as a method in service supply chain for coordinating the input through incentive systems across various parties. Contractual principles can be merged with functional features of service production and delivery to an integrated framework for realizing how operational and contractual aspects interact and develop each other (Lillrank \& Särkkä, 2011). According to He, Ghobadian, Gallear, Beh, and O'Regan (2016), there are five major reasons for service supply chain diversification compared with manufacturing supply chain: (1) services comprises all business related activities except for manufacturing, agriculture, and mining; (2) there is significant diversity between and within sectors in service supply chains; (3) compared with manufacturing supply chains, value chain procedures of service companies are less standardized; (4) service supplying is mainly decentralized due to decisions which are taken locally to fulfil various customers requirement; and (5) assessing and measuring service performance is complicated due to processes uncertainty, considerable human engagement, and service output variations due to diverse customers requirement.

\subsection{Agent based modelling}

Simulation by using Agent-based modelling (ABM) is applicable when different participants exist in a system, and they act independently, interact with each other, respond to system alteration, and their total activity is nonlinear and not resulted from summation of each participant' behaviour. These requirements describe a typical service delivery operation.

Agent-based models are created with objects called as agents that interact within an environment. Agents are distinct part of the program and represent modelling actors which can be individuals, organizations or bodies such as nations-states. From pragmatic modelling view, agents have following specific characteristics (Macal \& North, 2009):

- Agents are social and communicate with other agents.

- Agents are independent and self-directed.

- Agents are traceable, discrete or modular, each entity with set of features and principles controlling its behaviour and decision-making capability.

- Agents are located and living in an environment in which agents interact with other ones.

- Agents can have goals to accomplish considering its behaviour (not particularly maximization objectives).

- Agents are flexible and have capability to learn and adjust its behaviour based on experience 
Features of agent-based modelling can be described as:

(1) Ontological correspondence: direct association exists between the model computational agents and realworld actors which facilitates model designing and outcome interpretation.

(2) Diverse agents: each agent acts according to its own principles and preferences.

(3) Environment representation: the environment in which agents are acting directly, can be represented in an agent-based model. Furthermore, it can include physical aspects such as physical or geographical hurdles, other agents' impact on surrounding district, and effect of factors such as crowding and resource reduction.

(4) Agent interactions: it is possible to simulate interactions between agents.

(5) Bounded rationality: it can be defined as people are restricted in their cognitive capabilities and the level to which they can optimize their performance, and in an agent-based model, is possible to create bounded rational agents.

(6) Learning: Agent-based models can simulate learning in both individual and population levels, and it can be modelled in three ways; individual, evolutionary and social learning (Gilbert, 2008).

The challenges of service operations are related to structures and performance in a wide range: These include service quality, service performance, manufacturing principles, service dynamics, customer related special requirements, coordination of information between supply chain actors, capacity management, demand management, outsourcing, and service provider selection (Sakhuja et al., 2016). Servitization generally shifts the focus from delivering the materials to synchronization of workforce, tools and materials needed for the service delivery. Agent based modelling can help visualizing a combined view to demonstrate the expected performance in various conditions.

In designing a simulation framework, components are classified under three different clusters: (1) functional, (2) organizational, and (3) structural. Functional components encompass supply chain activities that are modelled as services - these elements are processing information by using resources, which are based on logical rules; Organizational components are simulated as intelligent agents that represent business partners and structural components represent facilities in supply chain providing resources and constraints in the ambient environment. All components can be modified for assessing different scenarios. Furthermore, communications between members assimilated through interactions protocols, and they are conducted as set of services which can be initiated by members. These services set standard messages comprising business documents to be changed. This way, it is possible to have various execution of internal activities of each member and create an ordinary control on information visibility shared between members (Dorigatti, Guarnaschelli, Chiotti, \& Salomone, 2016).Manufacturers tranforming toward services and increasing the service part of the PSS, need to have tools that are able to handle the delivery. Agent based modelling has been used to capture the service operation in the fields of transportation (Hilletofth \& Lättilä 2012), food assistance and locality services (Leung et al 2015), health care services (Rouzafzoon \& Helo, 2016), and evacuation planning (Esmaelian, Tavana, Santos Arteaga, \& Mohammadi, 2015). This kind of examples are typical for service delivery in a PSS context: coordination of transportation syncronized with other operations, operations that include people as both servers and customers in interaction, and managing time and space related constraints are often presenting challenges. Traditional discrete-event simulation has shown strong performance with material flow related modelling, but the ABM can include the unique customer demand features of service and combine with the geographical aspects in service delivery.

\section{TOOL PRESENTATION - USING ABM}

Agent based modelling can be applied for testing various scenarios of service interaction and operational delivery by combining rules instructing the agent behaviour and the world described by using geographical information. This kind of approach allows analysing many questions such as:

- Where to locate service centres?

- How different customer areas are served? 
- What is the performance of the service delivery at different times? (key performance indicators)

- What is the resource utilisation at different times?

- How system behaves under varying demand and supply conditions?

\subsection{Geographical information}

Servitization broadens the focus of delivery toward the actual customer locations: where the customer asset takes place or where the service operation needs to be planned at each time. The availability of public geographical information, including maps, geotagged location data, population data and open data provided by public administration has enabled new possibilities for data scientists for modelling and visualizing data. GIS (geographic information systems) technology can contribute in service organizations to comprehend their market scope, the location of their clients, and how to allocate resources in the district to fulfil service demands. GIS has also been applied for economic analyses in macro-level for enhancing accuracy in trip cost and benefit transfers. Open accessible public data can be used to discover patterns, resolving complicated problems, and make data-driven decisions. For instance, logistics related service analyses can be performed by using OpenStreetMap (OSM) data source including diverse information such as routes types, speed limits, route directions and length. Maps and spatial analysis enable servitizing manufacturers to model transportation network, estimate accurate service time frame, increase sale, gain market share and decrease risk (Bateman, Jones, Lovett, Lake, \& Day, 2002).

A suitable service area can be estimated by using maps, road information and locating the service provider agent on the map. The reach for each possible location can be evaluated by time to access the service location. For example, based on OSM map and road information, three 10, 20, and 30 minutes' service areas are visualized in Figure 1. The service location would be in the Helsinki city centre and with combination of driving speed and roads, the access map is generated (Figure 1).

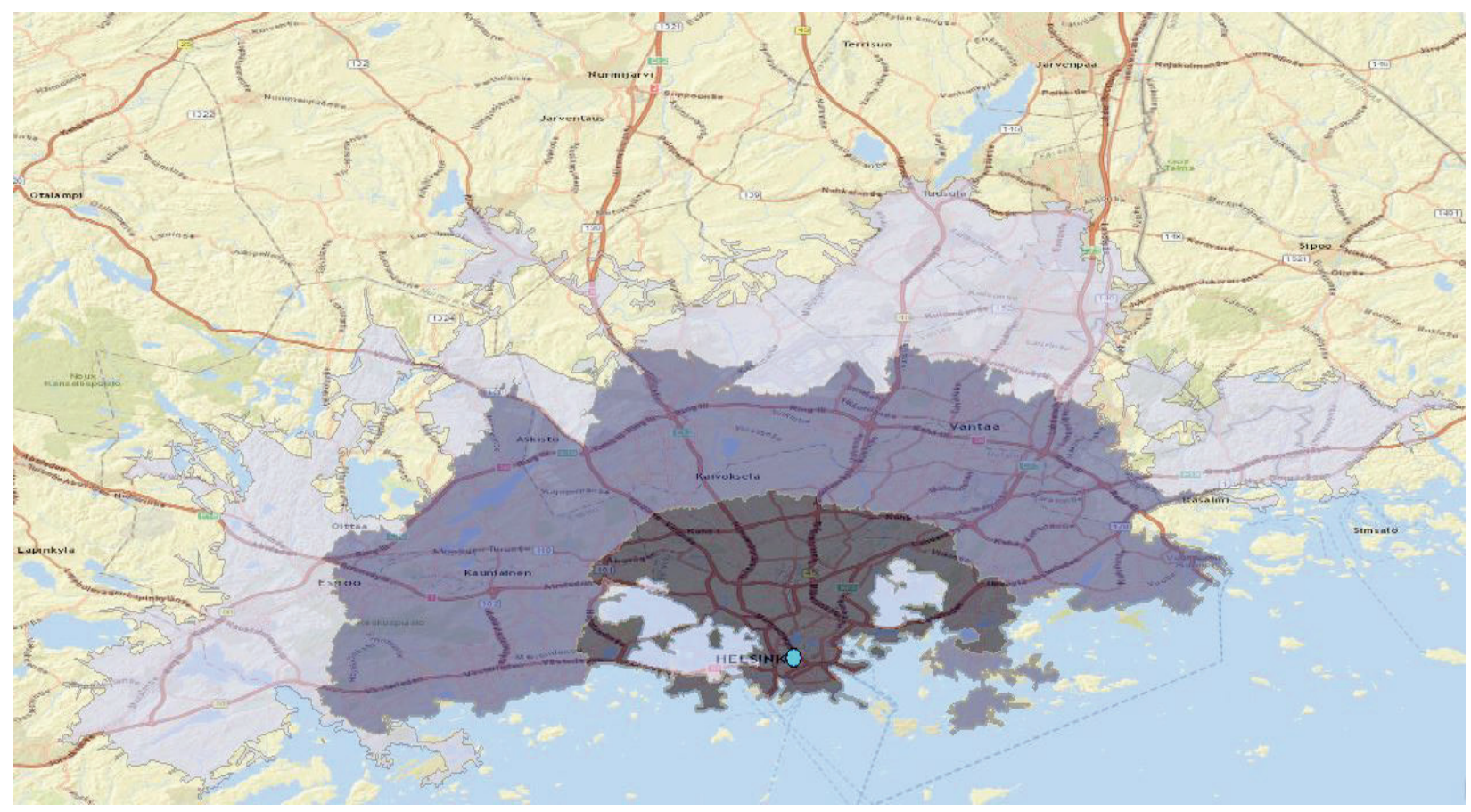

Figure 1 Helsinki service areas from OpenStreetMap data source.

Service providing access and reach is very often combined with customer density information and, in businessto-business (B2B) commerce, it can be even merged with companies density information. Population data can 
play a significant role in service oriented procedures. Population data is increasingly available in high details as open data and can be directly to applied in B2C context. Data is available very often in postal code level at least. Many countries, including Finland, is sharing the population data in matrix of $1 \mathrm{~km}^{2}$, which provides highly precise information on a very local level (Figure 2). Population data, including age and gender, is a good source for generating the customer agents. Population density can be a driver for probability of having a service need for a customer on certain location. In the same way for B2B situations, service providing access and service need for companies can be evaluated based on business density information. Many B2B operations have demand driven according to population density and in order to generate probabilities, this data may be used as input. Linking population to demand of services can be used directly as an assumption in a model or by using an intermediate variable. For example, products related to construction, retail, wholesale, healthcare and traffic are tightly linked to population. Road networks and other infrastructure is also provided by GIS systems. This information is highly useful for pure B2B cases as realistic information is available on transportation and access times for mobile fleets.

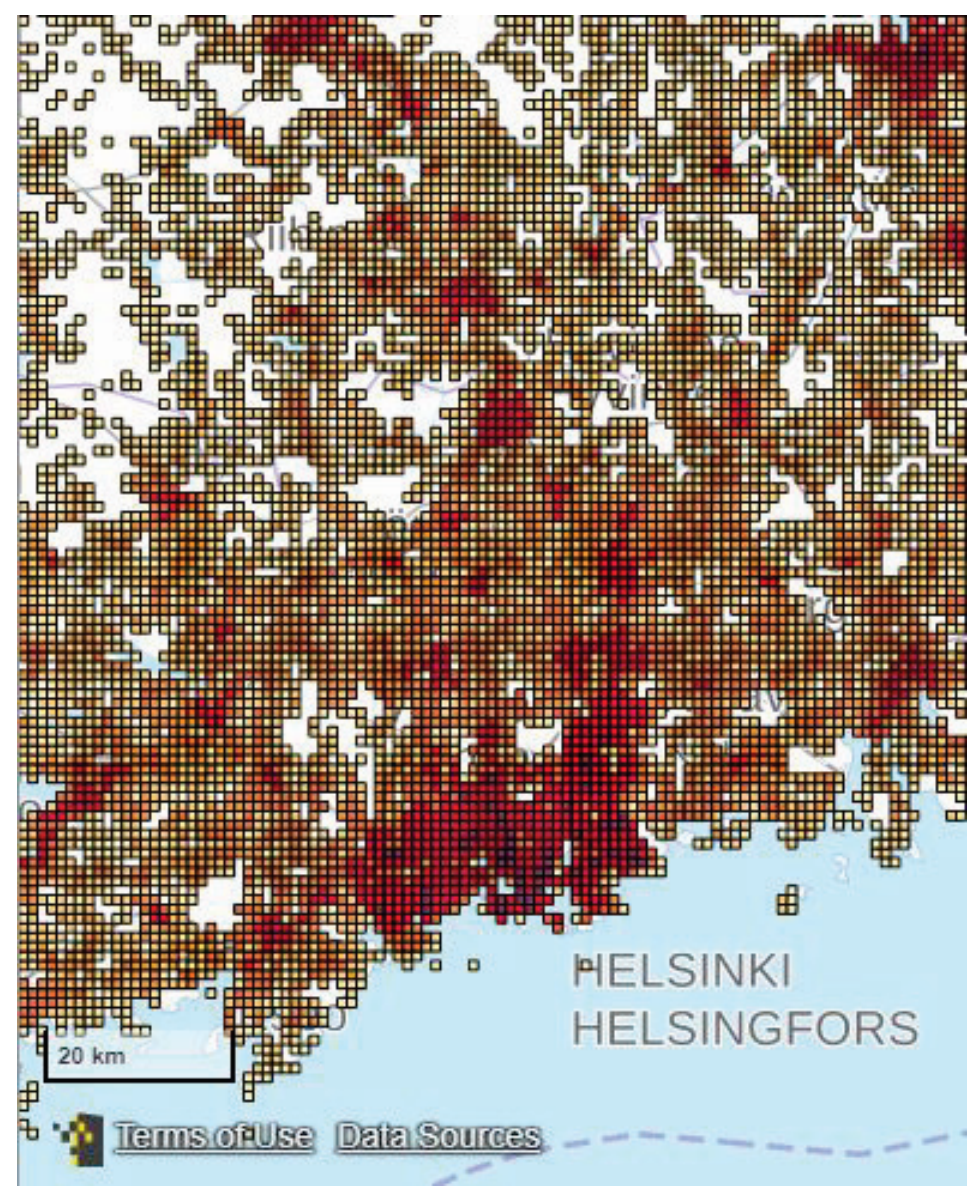

Figure 2 Population grid data $(1 \mathrm{~km} \times 1 \mathrm{~km})$ in Helsinki city (statistics Finland, 2015).

\subsection{Agent based simulation}

To demonstrate how agent-based modelling can be used to support service supply chain design, we consider a vehicle service centre example, where the impact of centralized and decentralized service structure can be evaluated based on capacity utilization. In this case, a manufacturer of vehicles is expanding the business to cover life-cycle services and needs to maintain a certain service level of customer assets in order to get recurrent payments. In this example, vehicle service centres are authorised service shops which provide repair and service operations after the purchase of a professional heavy vehicle. The service network can consist of a number of different types of service providing units, having location and performance as object properties. 
Customers are attracted to closest service locations or ones with shortest processing times and lead-time to service can be used as a performance indicator combing the travel time, queue time and the actual service delivery time. AnyLogic software was used to model the ABM simulation. Once the model has been constructed with agents and rules, the user can evaluate various conditions and extreme values regarding the number of service centres, their locations, operating working hours and location impact on operational performance are evaluated (see also Rouzafzoon \& Helo, 2016).

The simulation model focuses on following features:

- $\quad$ Service supply chain design by presenting network actors as simulation agents

- $\quad$ Key performance evaluation versus service location and geographical elements impact

- $\quad$ Demand pattern generation based on population density and geographical location

The first challenging issue is simulating population density in a way that it resembles to reality. Population data used to generate customers were provided by official Finland statistics data, which presents number of people categorized by gender and age in each square kilometre region. People are located based on their geographical coordinates with geographical information system feature of simulation software and Java function which retrieves population information. The linkage between population density and demand location for a service is an assumption, which can be adjusted to have a weaker or stronger correlation in addition to randomness. In this example, the assumption that customer demand follows the population density is taken as real-time tracking for customer asset is not available.Three potential service / repair shop locations suggested by managers, and in the next phase, customers are directed to the nearest repair centre. This process is implemented by Java functions which locates customers and repair centres based on their geographical coordinates. For instance, in (Figure 3), some agents and a service centre are located in Helsinki centre area. Customers move to a service / repair shop based on routing information which is provided by the OSM server in the software. Furthermore, routing setting is defined based on road network and the fastest routing method.

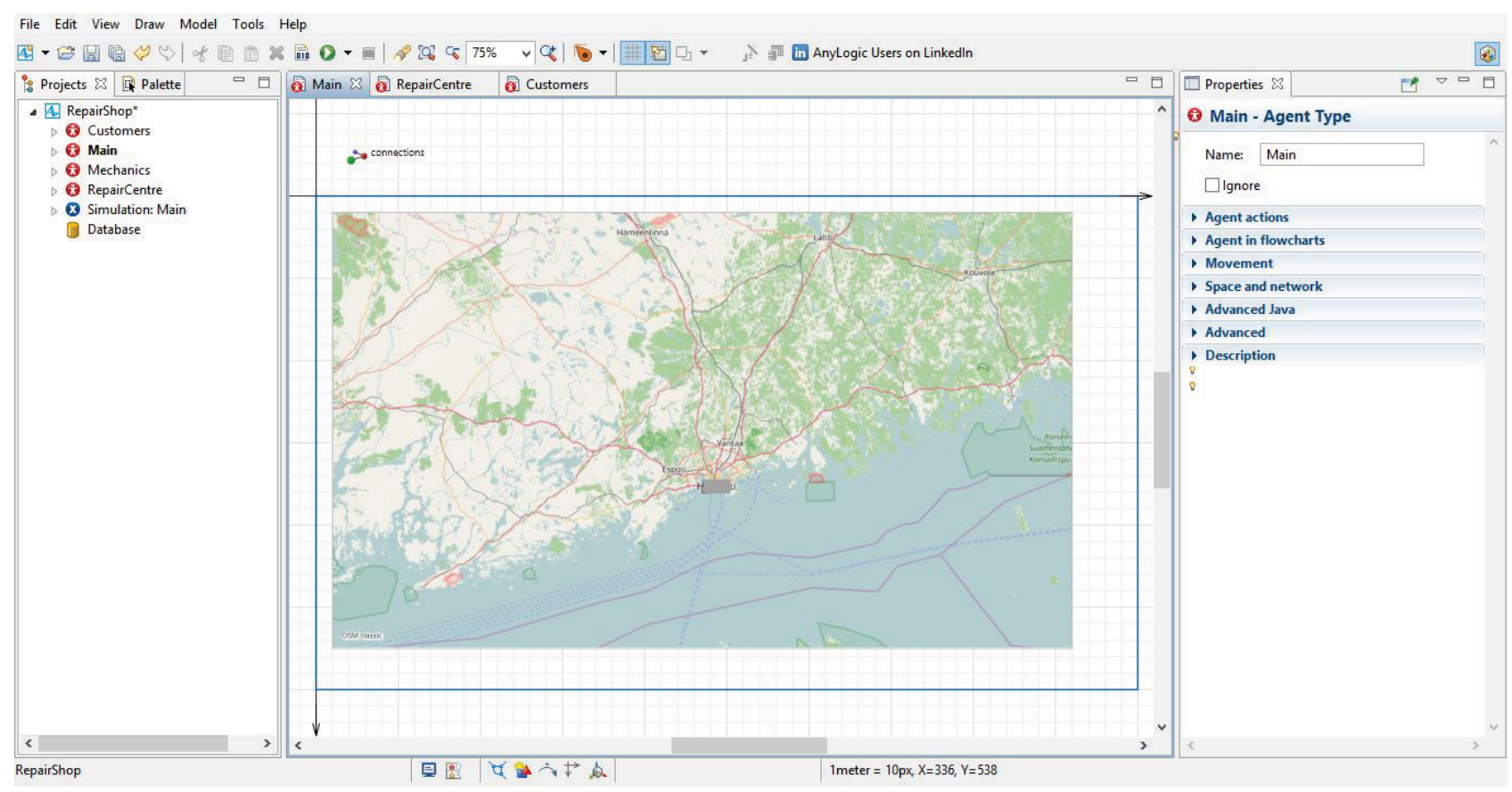

Figure 3 GIS map with located agents and a service centre - AnyLogic simulation software screenshot.

Agents are the key building blocks of simulation, and in this automobile service centre example, the object classes Customers, Repair shops, and Mechanics are created as agents. 
Customer agent is built of states such as NormalCondition, Broken, MovingToRepairShops and Repairing. Each person's vehicle originally is in normal condition and then based on a probability distribution, vehicles become broken and customer agent state changes to broken. Then, customers locate the nearest repair shop based on geographical coordinates and move toward it. When they arrive repair centres, process of automobile fixing begins. After repairing process, customers leave the repair shop and the agent status is converted to normal condition again, (Figure 4).

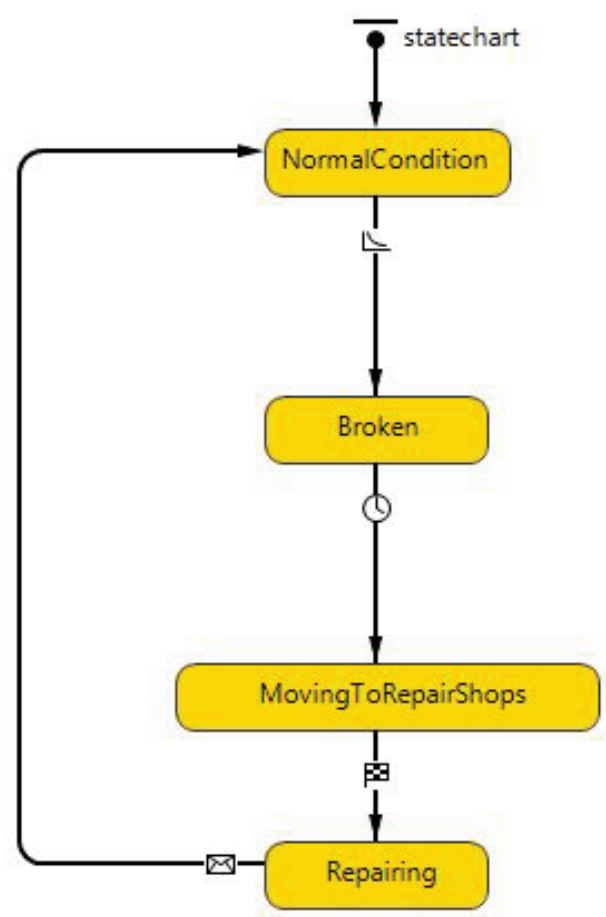

Figure 4 Customer processing states and transition within agent.

Every vehicle requires different service and repair, and system deal with large variety of tasks. Therefore, the automobile repair centres resemble to job shop system which is an order based production system with large number of various products manufactured in a small quantity. (Sharma \& Garg, 2012). In this study, the repair shop agent is built based on simple three steps (Figure 5).
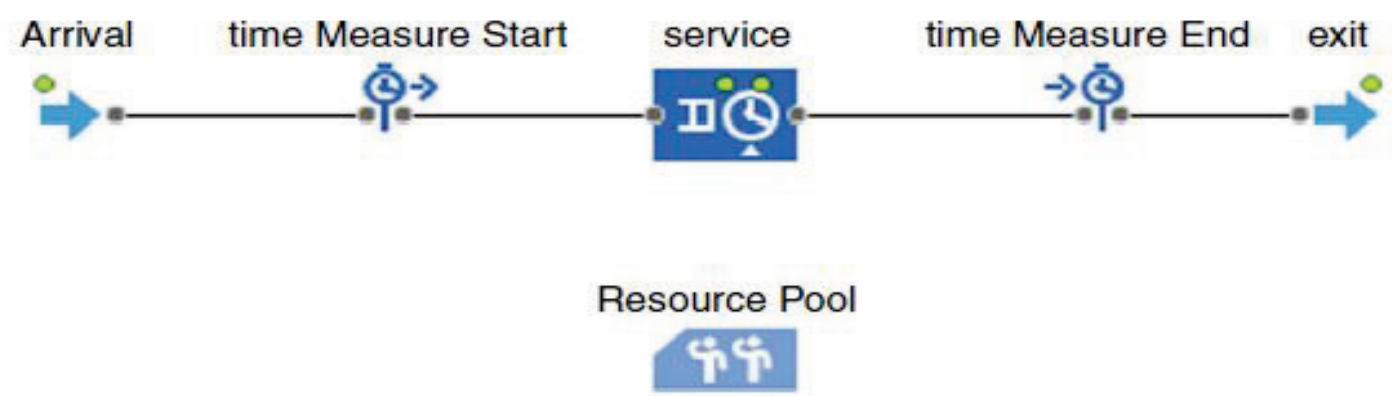

Figure 5 Customer flow structure in service delivery. 
Customers receive service based on first-in-first-out (FIFO) rule. There is a resource pool for mechanics, and if there is no available mechanic, they wait in a queue. Furthermore, service time is defined based on a probability distribution.

To evaluate the simulation outcome, different key performance indicators should be defined. Length of stay and number of customers in queue can be introduced as service level indicators. Customers' length of stay can be defined as the time between customers' arrival and leaving the repair shop. In addition, a capacity utilization indicator is created to evaluate service level and operation cost, while resource managers can detect if resources are under or over utilized. Resources include mechanics in repair centres, and capacity utilization measures the ratio between actual working hours and total possible working hours. In addition, a ratio of the number of customers is created to compare the number of customers entering and leaving repair shops. Key performance indicators are evaluated during the simulation and at the end of the simulation time (Table 1).

Table 1. Key performance indicators for evaluation, categorized according to agent type (example).

\begin{tabular}{|l|c|}
\hline Perspective & Key performance indicators \\
\hline $\begin{array}{l}\text { Customer perspective } \\
-\quad \text { Customer agent }\end{array}$ & Lead-time to complete the process \\
& - Time to access the service \\
\hline Service facility location cost of operation / customer \\
$-\quad$ Automobile repair centre attracting \\
$\quad$ customers and providing a service facility \\
$\quad$ for service agents & - Copacity utilisation \\
& - Service supply chain flexibility time in \\
& - demand increase \\
\hline Service provider agent & - Capacity utilisation for each resource type \\
Mechanic agent & - Queue time for each resource type \\
& - Actual cost per service transaction \\
\hline
\end{tabular}

The described approach is too generic and can be applied to model various service interactions. Customers may interact with each other and spread demand (word of mouth effect) or have a varying need of service, as well as preferences for cost, lead-time or quality related parameters. Probability of each customer parameter is randomized according to a statistical distribution and the simulation can show how key performance indicators behave under different conditions.

Key performance indicators need to be built based on exact need of a company. Agents can provide information on actual resource consumption, event times and success rates of events. This is then translated into lead-time, costs, quality, on-time delivery and other performance metrics, or toward more advanced indicators such as sustainability related KPIs (Tseng et al 2016).

Scenarios vary from one service operation to another. For instance, according to Pramod, Banwet, and Sarma (2016) the major issues in telecom service were stated as resistance to alteration, absence of trust in supply chain linkage, fear of information system or supply chain breakdown, low level of supply chain coordination, forecasting ambiguity, demographical aspects, and diversity between supply chain partners. Supply- and demand-related scenarios need to be built case by case as well as the key performance indicators, which are often company specific. 


\section{MANAGERIAL CONCLUSION}

The process of designing and managing product-service systems is a demanding task. Systematic approach is needed to combine the data available for analysis and to test different scenarios. Aspects of structures, operational performance, perceived service level, business models and role of technology need to be defined (Helo et al 2017). Large number of data needs to be analysed in complex situations, where system elements interact with each other dynamically. The behaviour may depend on previous actions. Updated and revised demand data may be needed to input for analysis and rapid decision support. For this kind of task, new tools beyond spreadsheet analytics is needed.

Contemporary agent-based simulation approach can solve the problem at least partially and be applied and developed in a service supply chain design. Modelling customers and service providers as intelligent agents with geographical location information is a generic approach for several service supply chains. Managers can evaluate the performance of service supply chain and there is possibility to conduct what-if analysis for assessing the decisions impact in a safe environment.

Agent based modelling requires knowledge of computer simulation and programming. Despite the learning curve, the advantages of agent-based modelling; customer-level analysis is concentrated and not only materials flow or resource utilization is focused compared to traditional discrete event simulation.

Agents can interact with each other and an agent has geographical location which can influence on its behaviour. The agents-based simulation approach can be used to analyse sophisticated customer-oriented systems, particularly for generating service network strategies. Service location analysis can be merged with service levels and operation performance associated KPI's in the same model. For analysing situations such as peak demand, time trigger events and demand patterns can be introduced.

Use of ABM can be incorporated in "DevOps" activities combining quality assurance, operational management of services and continuous developments of services. Smart machinery and fleets of installed base will provide vast quantities of fresh data, which can be utilized for service business improvements. Agentbased simulation provides new opportunity to harmonize supply, demand and KPI behaviour. ABM approach can capture the intangible aspects of the service process, combine the "big data" from public sources (open data) and company specific historical details of demand and service/operations.

The limitations of the approach are related to more complex modelling which requires programming skills in some extent. However, the ABM tools enable more comprehensive views and making decisions which are based on data and documented assumptions.

\section{REFERENCES}

Bateman, I. J., Jones, A. P., Lovett, A. A., Lake, I. R., \& Day, B. (2002). Applying geographical information systems (GIS) to environmental and resource economics. Environmental and resource economics, 22(1), 219269.

Bhattacharjee, P., \& Ray, P. K. (2014). Patient flow modelling and performance analysis of healthcare delivery processes in hospitals: A review and reflections. Computers \& Industrial Engineering, 78, 299-312. doi: 10.1016/j.cie.2014.04.016

Dorigatti, M., Guarnaschelli, A., Chiotti, O., \& Salomone, H. E. (2016). A service-oriented framework for agent-based simulations of collaborative supply chains. Computers in Industry, 83, 92-107.

Esmaelian, M., Tavana, M., Santos Arteaga, F. J., \& Mohammadi, S. (2015). A multicriteria spatial decision support system for solving emergency service station location problems. International Journal of Geographical Information Science, 29(7), 1187-1213.

Gilbert, N. (2008). Agent-based models: Sage. 
He, Q., Ghobadian, A., Gallear, D., Beh, L.-S., \& O'Regan, N. (2016). Towards conceptualizing reverse service supply chains. Supply Chain Management: An International Journal, 21(2), 166-179. doi: doi:10.1108/SCM01-2015-0035

Helo, Petri, Gunasekaran, Angappa, Rymaszewska, Anna (2017). Designing and Managing Industrial ProductService Systems. SpringerBriefs in Operations Management, Springer.

Hilletofth, P., \& Lättilä, L. (2012). Agent based decision support in the supply chain context. Industrial Management \& Data Systems, 112(8), 1217-1235.

Leung, Z. C., Pun-Cheng, L. S., \& Ho, A. P. (2015). Locality service review and planning with GIS: A pilot study of spatial analysis of poverty data in Hong Kong. Journal of Technology in Human Services, 33(1), 3852 .

Lillrank, P., \& Särkkä, M. (2011). The service machine as a service operation framework. Strategic Outsourcing: An International Journal, 4(3), 274-293.

Macal, C. M., \& North, M. J. (2009). Agent-based modeling and simulation. Paper presented at the Winter simulation conference.

Pramod, V., Banwet, D., \& Sarma, P. (2016). Understanding the barriers of service supply chain management: an exploratory case study from Indian telecom industry. OPSEARCH, 53(2), 358-374.

Rouzafzoon, J., \& Helo, P. (2016). Developing service supply chains by using agent based simulation. Industrial Management \& Data Systems, 116(2), null. doi: doi:10.1108/IMDS-05-2015-0220

Sakhuja, S., Jain, V., Kumar, S., \& Chandra, C. (2016). A Structured Review of Service Supply Chain Discipline: Potentials, Challenges, and Integrated Framework. Journal of the Academy of Business Education, 17.

Sharma, R., \& Garg, S. (2012). Capacity planning and performance measurement for automobile service centre using simulation. International Journal of Modelling in Operations Management, 2(3), 288-308.

Tseng, M.-L., Lim, M. K., Wong, W.-P., Chen, Y.-C., \& Zhan, Y. (2016). A framework for evaluating the performance of sustainable service supply chain management under uncertainty. International Journal of Production Economics. 